\title{
The plantaris muscle - rare relations to the neurovascular bundle in the popliteal fossa
}

\author{
Ł. Olewnik ${ }^{1}$, M. Podgórski², M. Polguj ${ }^{3}$, M. Topol ${ }^{1}$ \\ ${ }^{1}$ Department of Normal and Clinical Anatomy, Medical University of Lodz, Poland \\ 2Polish Mother's Memorial Hospital Research Institute, Lodz, Poland \\ ${ }^{3}$ Department of Angiology, Medical University of Lodz, Poland
}

[Received: 29 December 2017; Accepted: 5 April 2018]

The plantaris muscle is characterised by morphological variability, both for origin and insertion, and may sometimes be absent. Its strength allows the ligament to be used for reconstruction of other tendons and ligaments. This report presents the rare placements and course of the plantaris muscle in relation to the neurovascular bundle. In this case, the hypertrophy of this muscle might cause pressure on the tibial nerve and produce symptoms similar to sciatica. (Folia Morphol 2018; 77, 4: 785-788)

Key words: plantaris muscle, neurovascular bundle

\section{INTRODUCTION}

The plantaris muscle (PM) consists of a short, slim, spindle-shaped muscle belly and a long tendon $[3,22,23]$. The origin of the muscle is located on the popliteal surface of the femur above the lateral condyle and on the knee joint capsule; further along, the muscle belly becomes a long tendon, which most often inserts to the medial side of the calcaneal tuberosity [3].

The muscle demonstrates considerable morphological variability, both for origin and insertion $[1,20,22,26]$. In rare cases, the PM can be absent $[9,20,22,25]$. Knowledge of the morphological variability of this muscle is essential for all clinicians, because the course of the plantaris tendon can cause Achilles tendinopathy, and this tendon is used for reconstruction of other tendons and ligaments. In recent years it has been proposed that the rupture of the muscle should be classified under the term 'tennis leg'.

The present report describes a rare relationship between the PM and the neurovascular bundle in the popliteal fossa. To our knowledge, this is the first description of such a case.

\section{CASE REPORT}

A 71-year-old male cadaver was subjected to routine anatomical dissection for research and teaching purposes at the Department of Normal and Clinical Anatomy, Medical University of Lodz. A dissection of the lower limb was performed by traditional anatomical dissection [21-23]. During the dissection, the PM was found to possess an anomalous origin and course. In contrast to the typical origin position located above the lateral femoral condyle, the muscle belly was observed to attach to the joint capsule of the knee, medially to the lateral head of the gastrocnemius muscle (Fig. 1). This determined its anomalous further course. The muscle belly ran posterior to the tibial nerve and the popliteal vessels. After the passage of the belly, the tendon ran posterior to the tibial nerve.

Following this, after entering into the space between the gastrocnemius muscle and soleus muscle, the tendon of the PM ran to the medial part of the leg. This type was characterised by a very wide insertion encircling the posterior and medial surfaces of the calcaneal tendon (Fig. 2). This type of insertion was characterised by tendon enlargement - extension point [22].

Address for correspondence: $Ł$. Olewnik, MD, Department of Normal and Clinical Anatomy, Interfaculty Chair of Anatomy and Histology, Medical University of Lodz, ul. Narutowicza 60, 90-136 Łódź, Poland, tel: +48 4263049 49, e-mail: lukasz.olewnik@umed.lodz.pl 


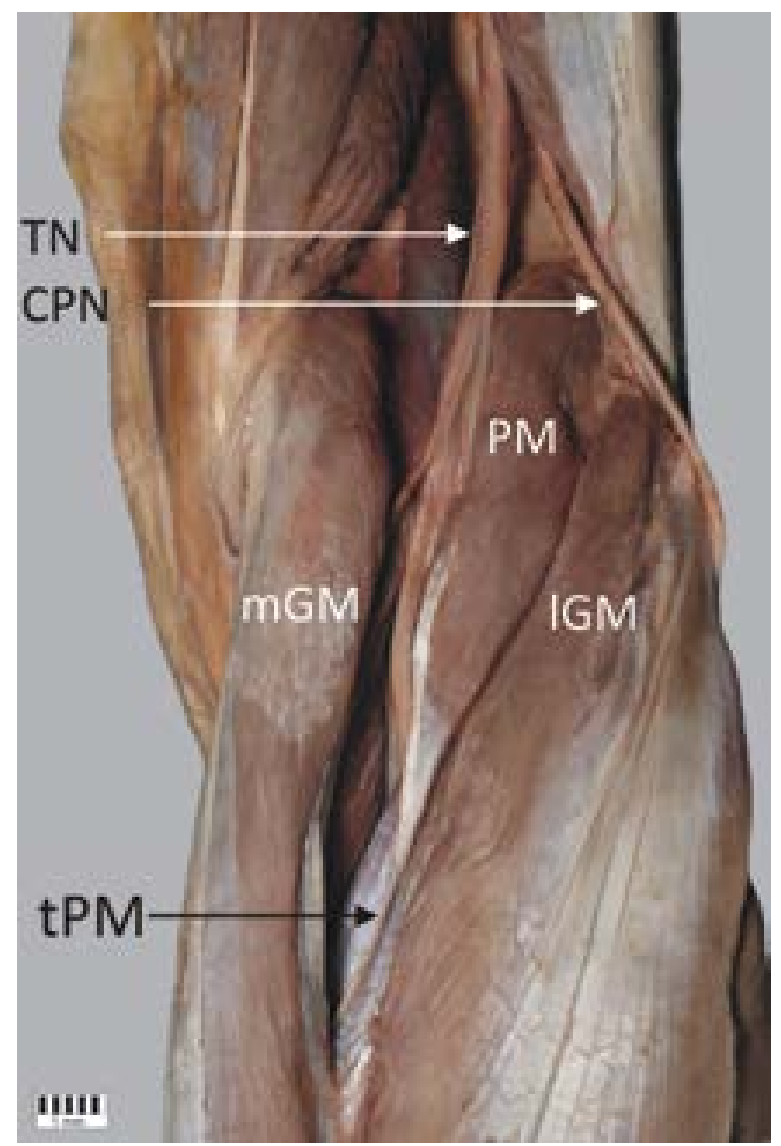

Figure 1. Rare anatomical variant of plantaris muscle location; CPN - common fibular nerve; IGM - lateral head of the gastrocnemius muscle; $\mathrm{mGM}$ - medial head of the gastrocnemius muscle; $\mathrm{PM}$ - plantaris muscle; TN - tibial nerve; tPM — tendon of the plantaris muscle.

The PM was cut, photographed and subjected to further measurements. The muscle was measured by an electronic calliper (Mitutoyo Corporation, Kawasaki-shi, Kanagawa, Japan). Each measurement was carried out twice with an accuracy of up to $0.1 \mathrm{~mm}$. The length of the muscle belly was $104.31 \mathrm{~mm}$ and its thickness was $4.92 \mathrm{~mm}$. The width of the tendon upon passing the muscle belly was $2.03 \mathrm{~mm}$. The total length of the tendon was $405.31 \mathrm{~mm}$.

The ratio between the tendon length and the overall length of muscle was $74.26 \%$.

\section{DISCUSSION}

The PM may be regarded as the vestigial remains of a primitive flexor of the toes, which acted together with the plantar aponeurosis [5].

Anomalies such as the presence of accessory muscle bellies or the fusion of one muscle with another have been observed. Although the possibility of an accessory muscle has been noted many times, only

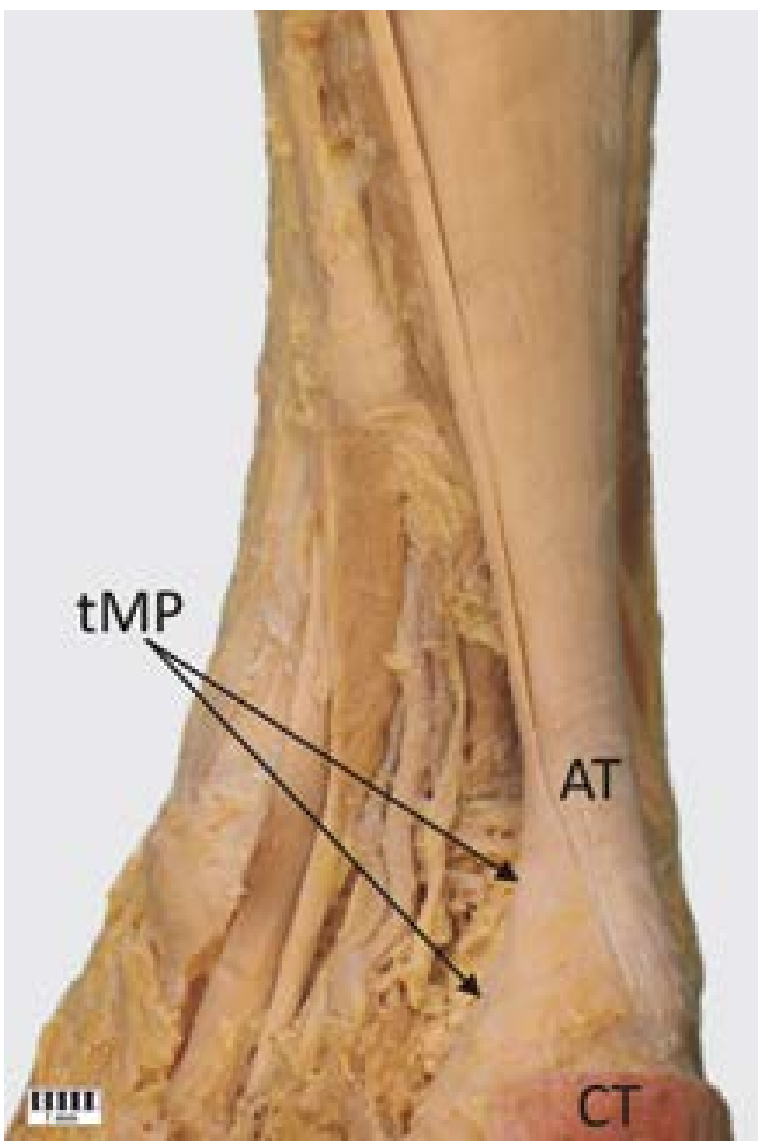

Figure 2. Insertion of the plantaris tendon muscle; AT — Achilles tendon; CT — calcaneal tuberosity; tPM — tendon of the plantaris muscle.

a few studies describe its presence within the leg [10]. The clinical significance of these variations depends on their location and potential impact on neighbouring structures [17].

In a magnetic resonance study of 1000 patients, Herzog [10] described the presence of an additional muscle in 63 patients, which accounted for $6.3 \%$ of all cases: 38 (7.5\%) men and 25 (5.1\%) women. The presence of a double plantaris muscle PM has also been described in a corpse of a 47-year-old woman by Kwinter et al. [16], who note the presence of a double muscle in the right lower limb and a typical single muscle in the left. Elsewhere, a double muscle was found in both the right and left lower limbs of the corpse of 45-year-old man [14]. As the occurrence of additional muscles can be confused in physical examination with a tumour of the popliteal region, it is important to be aware of the variations in muscle arrangement [18].

In the available literature, the term 'tennis leg' has stirred many controversies. Although the term is 
widely accepted to refer to ruptures or tears of the medial head of gastrocnemius muscle, some clinicians believe that it may also include the rupture or tearing of the medial head of gastrocnemius muscle or soleus muscle or PM [24].

This injury is observed most often in people who are physically active; it typically occurs during excessive stretching of the gastrocnemius muscle by strong dorsal flexion of the foot with simultaneous extension of the knee joint $[2,4,7,11,15,24]$. During such movement, the triceps surae muscle is subjected to eccentric work, resulting in the generation of active muscle tension with elongation $[6,13]$; as muscle elongation is accompanied by external forces which are much larger than those generated by the muscle, the patient experiences injury when the heel touches the floor. Those taking part in sports such as running, playing tennis, squash, climbing or skiing on the amateur or professional level are particularly susceptible to these injuries [7, 24]. Allard et al. [2] were the first to report a rupture of the PM. Hamilton et al. [8] described the first surgery in which such ruptures was observed. In studies conducted by Delgado et al. [6], PM rupture occurred in only two patients of 141 who were diagnosed with tennis leg.

Rohilla et al. [24] believe that injury indifferently from the muscle of the superficial layer of the posterior group of the leg can lead to tennis leg symptoms - only the intensity of pain is different. They suggest that patients experiencing a rupture of the PM will experience much less pain and will recover full mobility faster than those with rupture of the gastrocnemius or soleus muscle. Magnetic resonance imaging or ultrasound examination are the best diagnostic approaches $[4,6,15]$; however, ultrasound is considered to be the gold standard in the diagnosis of tennis leg, as it allows such disease units as Bartker's cyst ruptures or deep vein thrombosis to be excluded [7]. It is therefore important to consider whether the type of attachment and the location of the muscle may affect the occurrence of major pain in the case of tennis leg.

The removal of the PM does not generally impede the function of the lower limb of patients with normally functioning gastrocnemius and soleus muscles $[16,25]$. The tendon is strong, and can be used for reconstructing the tendons of the hand, as well as the anterior talofibular and calcaneofibular ligaments $[12$, $23,25]$. In the present case, the course of the distal tendon is characterised by enlargement, which should be taken into account when the tendon is removed for transplant. Knowledge of the insertion of the plantaris tendon and its variant of course is essential for the proper planning of its transplantation $[22,23]$.

Some authors have also described examples of the PM following an unusual course in relation to the neurovascular bundle. Earlier reports indicate that the PM may be trapped between the tibial nerve and its branches running to the soleus muscle [19]. Kotian et al. [12] observed a rare variation of the PM: it begins with a normal origin on the lateral condyle of the femur but then divides into two bellies, superior and inferior, which differed extensively in relation to the popliteal vessels and tibial nerve [12]. The superior belly ran forward in relation to the two sets of structures, while the spindle-shaped, inferior belly ran backwards in relation to the popliteal vessels, the main trunk of the tibial nerve and the branches running to the lateral head of the gastrocnemius muscle [12]. The present case report describes a PM with an unusual course, one which runs posterior to the tibial nerve. It can be assumed that in this case, hypertrophy of the muscle can place pressure on the tibial nerve and produce symptoms similar to sciatica.

\section{CONCLUSIONS}

We-presented a PM of atypical origin and a course. Due to its superficial alignment it might mimic a mass in the popliteal region. Elongated and twisted course may predispose to its injury. Finally, crossing of the neurovascular bundle can result in a tibial nerve compression.

\section{Acknowledgements}

The authors wish to express their gratitude to all those who donated their bodies to medical science.

\section{REFERENCES}

1. Aderval Aragão J, Prado Reis F, Ribeiro Guerra D, et al. The occurrence of the plantaris muscle and its muscle-tendon relationship in adult human cadavers. Int J Morphol. 2010; 28(1), doi: 10.4067/s0717-95022010000100037.

2. Allard JC, Bancroft J, Porter G. Imaging of plantaris muscle rupture. Clin Imaging. 1992; 16(1): 55-58, indexed in Pubmed: 1540866.

3. Bergman RA, Afifi AK, Miyauchi R. Anatomy Atlases: Illustrated Encyclopedia of Human Anatomic Variation - Anatomical Variation | Radiology Anatomy | Anatomy Atlas. 2015. http://www.anatomyatlases.org/AnatomicVariants/ AnatomyHP.shtml (Accessed 6 Feb 2017).

4. Bianchi S, Martinoli C, Abdelwahab IF, et al. Sonographic evaluation of tears of the gastrocnemius medial head ("tennis leg"). J Ultrasound Med. 1998; 17(3): 157-162, indexed in Pubmed: 9514167. 
5. Daseler E, Anson B. The plantaris muscle: an anatomical study of 750 specimens. J Bone Hoint Surg Am. 1943: 822-827.

6. Delgado GJ, Chung CB, Lektrakul N, et al. Tennis leg: clinical US study of 141 patients and anatomic investigation of four cadavers with MR imaging and US. Radiology. 2002; 224(1): 112-119, doi: 10.1148/radiol.2241011067, indexed in Pubmed: 12091669.

7. Flecca D, Tomei A, Ravazzolo N, et al. US evaluation and diagnosis of rupture of the medial head of the gastrocnemius (tennis leg). J Ultrasound. 2007; 10(4): 194-198, doi: 10.1016/j.jus.2007.09.007, indexed in Pubmed: 23396898.

8. Hamilton W, Klostermeier T, Lim EV, et al. Surgically documented rupture of the plantaris muscle: a case report and literature review. Foot Ankle Int. 1997; 18(8): 522-523, doi: 10.1177/107110079701800813, indexed in Pubmed: 9278749.

9. Harvey FJ, Chu G, Harvey PM. Surgical availability of the plantaris tendon. J Hand Surg Am. 1983; 8(3): 243-247, indexed in Pubmed: 6875222.

10. Herzog RJ. Accessory plantaris muscle: anatomy and prevalence. HSS J. 2011; 7(1): 52-56, doi: 10.1007/s11420010-9175-y, indexed in Pubmed: 22294958.

11. Jarolem KL, Wolinsky PR, Savenor A, et al. Tennis leg leading to acute compartment syndrome. Orthopedics. 1994; 17(8): 721-723, indexed in Pubmed: 7971525.

12. Kotian SR, Sachin KS, Bhat KMR. Bifurcated plantaris with rare relations to the neurovascular bundle in the popliteal fossa. Anat Sci Int. 2013; 88(4): 239-241, doi: 10.1007/ s12565-013-0184-z, indexed in Pubmed: 23771697.

13. Koulouris G, Ting AYI, Jhamb A, et al. Magnetic resonance imaging findings of injuries to the calf muscle complex. Skeletal Radiol. 2007; 36(10): 921-927, doi: 10.1007/ s00256-007-0306-6, indexed in Pubmed: 17483942.

14. Kum Rana K, Das S, Verma R. Double plantaris muscle: a cadaveric study with clinical importance. Int J Morphol. 2006; 24(3), doi: 10.4067/s0717-95022006000400032.

15. Kwak HS, Lee KB, Han YM. Ruptures of the medial head of the gastrocnemius ("tennis leg"): clinical outcome and compression effect. Clin Imaging. 2006; 30(1): 48-53, doi: 10.1016/j.clinimag.2005.07.004, indexed in Pubmed: 16377485.

16. Kwinter D, Lagrew J, Kretzer J, et al. Unilateral double plantaris muscle: a rare anatomical variation. Int
J Morphol. 2010; 28(4): 1097-1099, doi: 10.4067/s071795022010000400018.

17. Macedo TA, Johnson CM, Hallett JW, et al. Popliteal artery entrapment syndrome: role of imaging in the diagnosis. AJR Am J Roentgenol. 2003; 181(5): 1259-1265, doi: 10.2214/ ajr.181.5.1811259, indexed in Pubmed: 14573416.

18. Montet X, Sandoz A, Mauget D, et al. Sonographic and MRI appearance of tensor fasciae suralis muscle, an uncommon cause of popliteal swelling. Skeletal Radiol. 2002; 31(9): 536-538, doi: 10.1007/s00256-002-0496-x, indexed in Pubmed: 12195508.

19. Nayak SR, Krishnamurthy A, Prabhu LV, et al. Additional tendinous origin and entrapment of the plantaris muscle. Clinics (Sao Paulo). 2009; 64(1): 67-68, doi: 10.1590/s1807-59322009000100012, indexed in Pubmed: 19142554.

20. Nayak SR, Krishnamurthy A, Ramanathan L, et al. Anatomy of plantaris muscle: a study in adult Indians. Clin Ter. 2010; 161(3): 249-252, indexed in Pubmed: 20589356.

21. Olewnik $\measuredangle$, Podgórski $M$, Polguj $M$, et al. Anatomical variations of the pronator teres muscle in a Central European population and its clinical significance. Anat Sci Int. 2018; 93(2): 299-306, doi: 10.1007/s12565-017-0413-y, indexed in Pubmed: 28849397.

22. Olewnik $\measuredangle$, Wysiadecki G, Polguj M, et al. Anatomic study suggests that the morphology of the plantaris tendon may be related to Achilles tendonitis. Surg Radiol Anat. 2017; 39(1): 69-75, doi: 10.1007/s00276-016-1682-1, indexed in Pubmed: 27155667.

23. Olewnik $\measuredangle$, Wysiadecki G, Polguj $M$, et al. The report on the co-occurrence of two different rare anatomic variations of the plantaris muscle tendon on both sides of an individual. Folia Morphol. 2017; 76(2): 331-333, doi: 10.5603/ FM.a2016.0069, indexed in Pubmed: 27813626.

24. Rohilla S, Jain N, Yadav R. Plantaris rupture: why is it important? BMJ Case Rep. 2013; 2013, doi: 10.1136/bcr2012-007840, indexed in Pubmed: 23345486.

25. Simpson SL, Hertzog MS, Barja RH. The plantaris tendon graft: an ultrasound study. J Hand Surg Am. 1991; 16(4): 708-711, indexed in Pubmed: 1880370.

26. van Sterkenburg MN, Kerkhoffs GM, Kleipool RP, et al. The plantaris tendon and a potential role in mid-portion Achilles tendinopathy: an observational anatomical study. J Anat. 2011; 218(3): 336-341, doi: 10.1111/j. 1469-7580.2011.01335.x, indexed in Pubmed: 21323916. 